\title{
Determining Changes in Green Cover in Urban Areas
}

\author{
Monika Bagade ${ }^{1}$, Dr.Ramchand Hablani ${ }^{2}$, Ajit Dharmik ${ }^{3}$ \\ ${ }^{1,2}$ Shri Ramdeobaba College of Engineering and Management, Nagpur, India \\ ${ }^{3}$ 6Simplex Software Solution Pvt Ltd, Nagpur, India \\ bagademk@rknec.edu, hablanir@rknec.edu, ajitdharmik@6simplex.co.in
}

\begin{abstract}
In India, urban development is showing a negative effect on green cover and climate. A decrease in a green cover is a critical problem on earth. Geographic Information system is the best technique for location analysis. The GIS help us to get required data related to desired location and visualize it. In this paper, Nagpur, a city in the Maharashtra state of India is chosen as a study area. To detect the changes of green cover in a selective area for a different time, a change detection technique is used. Landsat8 satellite image within the year 2014 to 2020 is used to recognize a green cover change. Normalized Difference Vegetation Index (NDVI) method is used to estimates the mass of vegetation present in a satellite image. By using the NDVI value, a histogram is shown and compared to detect the changes in NDVI. The result shows, NDVI is higher for more number of pixels of an image of the year 2014 and it decreases for an image of the year 2020. Which shows the differences in the green cover of an urban area.
\end{abstract}

Key words: Change Detection, Changes in green cover, GIS, NDVI, Satellite Image, Vegetation.

\section{INTRODUCTION}

Most of the atmospheric impacts of urbanization are associated with a green cover. Degradation in green space may cause many problems for animals and humans. Green cover and urban land as a class of land use is an essential matter in almost all countries and cities. Every city administration must know if the city's green cover is increasing or decreasing.

In this study, we are using Landsat 8 satellite images. Landsat8 satellite was launched on date 11 February 2013. Therefore this study is going to be on data which is 2013 onwards. Landsat8 satellite is designed for the imagery to be applied in the agriculture, government, and education field. These imageries can be used to monitor city and road construction, deforestation, agricultural practices, and changes in sea ice. Landsat8 is implemented with two sensors which are OLI and TIRS. These two sensors collect data as an image with bands, for nine shortwave bands and two long wave thermal bands.

Satellite image analysis through some techniques helps us to control and identify these changes in the right way. Such changes can be found by comparing the same place satellite imagerywith a difference of years. Change detection results are very important to know the relation between human interactions with the environment in order to have greater recognition and decision making [2].

A technique that is used on such a satellite image for vegetation indication is NDVI. Greenness is described by this indicator which is vegetation index. It shows relative quantity and vegetation health for all pixel, in a satellite image. Researchers convert some satellite data into NDVI values to create images and different results that give some result of vegetation amount, type, and condition on land surfaces around the world.

Change detection is a measure of a property of a particular area that has changed between two or more periods. Change detection involves a comparison of satellite imagery of a particular area at different times.Change detection has generally used to assess deforestation, urban growth, the impact of a natural disaster like earthquake and land used, and land cover changes.

\section{LITERATURE REVIEW}

Many other authors have tried many techniques for change detection in vegetation. Every kind has its advantages, defects, and importance.

K. Bhandaria and G. K. Singh present an enhanced method for the study of satellite images based on the NDVI. The results show that the NDVI is extremely useful in identifying the surface features of the visible field which are remarkably beneficial for city planning and management [1].

Mushtaq Ahmad Ganie and Dr. Asima Nusrath present a step-wise computation method applied in ArcGIS 10.2.2 to know the apple area. The results show that NDVI indicates the health of vegetation. Higher NDVI indicates a higher amount of vegetation on the ground. NDVI of nonvegetation classes is usually lower than vegetation classes [4][18].

Carmelo Fichera, Giuseppe Modica \& Maurizio Pollino present Remote Sensing (RS) techniques and data, in union with landscape metrics and GIS, to characterize and analyze Land Cover (LC) and its differences. The result indicates that urbanization has considerably changed the LC of the research area, with notable land changes [7].

Martin, Hannes, Magiera, Annette, and Usman Babawuro Rainer present applicability of a site-specific remotesensing method like NDVI and MSAVI to seeing grassland degradation. The result shows that NDVI derived from 
multispectral reflectance was proved to detect grassland degradation at a high spatial resolution of $1.84 \mathrm{~m}$ to be appropriate to detect small vegetation damage spots in various grassland regions [8][16].

M.I. Haque, R. Basak present Pre-classification approach NDWI, CVA, and NDVI analysis to performing access to the changing scenario. Also, a post-classificationchange detection analysiswas performed. The result shows about $40 \%$ of the land cover of the total study area has been converted over 30 years period [10].

R. Das Kangabam presents approaches of digital change detection to assess thedifferences in the model of land use in Loktak Lake. The result shows the difference in land use patterns were found to be affecting the ecosystem also identify a need for proper land use planning [11].

R. MeliFokeng, W. GadingaForje, V. Meli recommends the design and implementation of supervised forest preservation policy [12].

JukkaMiettinen, Hans-Jürgen Stibig, FrédéricAchard, and Matthias Reusing present geographical, environmental, and traditional aspects of Southeast Asia from the view of forest degradation monitoring [13][14].

John G. Lyon, Ross S. Lunetta, and HaslinaHashim present a comparison between seven different vegetation indices for their value ofvegetation and change detection of land cover in State of Chiapas. The result shows that the NDVI difference technique is proved to be the best technique for vegetation change detection and they proposed a threshold method using NDVI value capable of identifying and classifying urban vegetation with the use of Very High Resolution [15][19].

\section{PORPOSED MODELLING}

\subsection{Study Area}

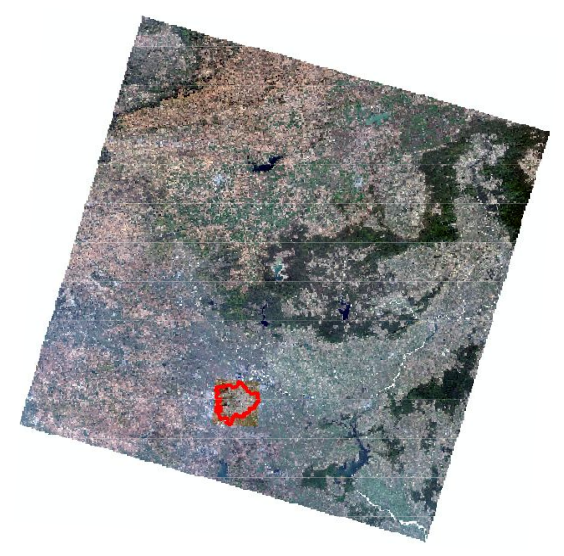

Figure 1: Natural Colour composite of Landsat 8 satellite image with highlighted study area.
The area selected for carrying out the present research covers the Nagpur city, the winter capital of the Maharashtra state in India. Nagpur is the third-largest city in Maharashtra. Nagpur was selected as the Second greenest city of India. Nagpur is also called the "Garden city of Maharashtra" and it is suitable to and deserving of being the "gateway to the Central Indian Forest". The city has the Zero Mile Stone placing the geological middle of India. It is situated almost at the geographic centre of the country. The latitude of Nagpur is 21.146633, and the longitude is 79.088860. The Nagpur district is pretty rich and various in its plant composition. Figure.1 shows highlighted study area which is Nagpur.

\subsection{Data Collection.}

Table 1: Landsat 8 Bands

\begin{tabular}{|c|c|c|c|}
\hline $\begin{array}{c}\text { Band } \\
\text { Number }\end{array}$ & Description & Wavelength & Resolution \\
\hline Band 1 & $\begin{array}{c}\text { Coastal / } \\
\text { Aerosol } \\
\end{array}$ & $\begin{array}{c}0.433 \text { to } \\
0.453 \mu \mathrm{m}\end{array}$ & 30 meter \\
\hline Band 2 & Visible blue & $\begin{array}{c}0.450 \text { to } \\
0.515 \mu \mathrm{m}\end{array}$ & 30 meter \\
\hline Band 3 & Visible green & $\begin{array}{c}0.525 \text { to } \\
0.600 \mu \mathrm{m}\end{array}$ & 30 meter \\
\hline Band 4 & Visible red & $\begin{array}{c}0.630 \text { to } \\
0.680 \mu \mathrm{m}\end{array}$ & 30 meter \\
\hline Band 5 & Near-infrared & $\begin{array}{c}0.845 \text { to } \\
0.885 \mu \mathrm{m}\end{array}$ & 30 meter \\
\hline Band 6 & $\begin{array}{c}\text { Short } \\
\text { wavelength } \\
\text { infrared } \\
\end{array}$ & $\begin{array}{c}1.56 \text { to } 1.66 \\
\mu \mathrm{m}\end{array}$ & 30 meter \\
\hline Band 7 & $\begin{array}{c}\text { Short } \\
\text { wavelength } \\
\text { infrared } \\
\end{array}$ & $\begin{array}{c}2.10 \text { to } 2.30 \\
\mu \mathrm{m}\end{array}$ & 60 meter \\
\hline Band 8 & Panchromatic & $\begin{array}{c}0.50 \text { to } 0.68 \\
\mu \mathrm{m}\end{array}$ & 30 meter \\
\hline Band 9 & Cirrus & $\begin{array}{c}1.36 \text { to } 1.39 \\
\mu \mathrm{m}\end{array}$ & 15 meter \\
\hline Band 10 & $\begin{array}{c}\text { Long } \\
\text { wavelength } \\
\text { infrared } \\
\end{array}$ & $\begin{array}{c}10.3 \text { to } 11.3 \\
\mu \mathrm{m}\end{array}$ & 100 meter \\
\hline Band 11 & $\begin{array}{c}\text { Long } \\
\text { wavelength } \\
\text { infrared }\end{array}$ & $\begin{array}{c}11.5 \text { to } 12.5 \\
\mu \mathrm{m}\end{array}$ & 100 meter \\
\hline
\end{tabular}

Landsat 8 satellite images and Arc Map 10.7.1 software were used in the study. Landsat 8 satellite images were downloaded from the source https://earthexplorer.usgs.gov. Downloaded Images are from the year 2014 to 2020 and contain the vegetation data. The downloaded images are in Geotiff format. While obtaining the satellite data, care was taken to assure that the data was cloud-free. The spacecraft LANDSAT 8 built by Orbital Science Corporation, under the agreement to NASA (National Aeronautics and Space Administration). The image was taken by LANDSAT 8 consists of 11 spectral bands [6]. Table.1 shows all 11 bands and its information. 


\subsection{Methodology}

This research used the Landsat 8 satellite image as input. But when Landsat 8 image gets downloaded it consists of 11 bands. Each band shows a grey colour image when looking towards it as a separate band. For the vegetation analysis purpose, it requires only three bands which are band 4 (RED), band 5 (NIR), and band 6 (SWIR). Therefore these three bands get composite by using Arc map software to get a three-band composite image that shows vegetation in Landsat 8 satellite image.Nagpur city is selected as a study area. Therefor A tool from Arc map is used to clip that highlighted part of Nagpur city as shown in Figure1.After that analysis of green cover is done on this image.

The methodology used for the study of green cover using a satellite image is the Normalized Difference Vegetation Index (NDVI). NDVI method requires separation of each band, to detect the vegetation index from a Multi-Spectral image which is the Satellite image. After each band is separated, the NDVI method is applied on feature like vegetation with different NDVI threshold values. In this research, we are showing the feature which is above the threshold values 0.1 . To extract the best result from a Satellite image of Nagpur city, NDVI threshold value is applied.

The NDVI is driven by the observation vegetation, which is the difference between the NIR and red band, it should be higher for greater chlorophyll quantity. In other terms, the level of greenness is similar to chlorophyll absorption. NDVI values change with the consumption of red light by plant chlorophyll and reflection of infrared radiation by water-filled leaf cells. All visible areas are taken by the Satellite camera in the form of bands through which features can be obtained after applying the NDVI method for various characteristics [9]. In this research, the NDVI method is used for obtaining the vegetation features presented in the three-band Satellite image of Nagpur City. NDVI is formulated using near-infrared (NIR) and visible red (R) light to check the appearance of a single band normalized vegetation index by collecting plants. Digital number (DN) and different band values are used for NDVI calculation. A digital number value occurs from the pixel of these bands [3].In other words, it is a pixel by pixel basis addition and subtraction of the value of the NIR band and the value of the red band which is then divided.NDVI for Landsat 8 images can be computed using the following formula.

NDVI $=($ Band $5-$ Band 4$) /($ Band $5+$ Band 4$)$

In this research, the extracted NDVI from Landsat 8 images were used to compute the green cover loss of Nagpur city during these 4 years. Resulting index value ranges from +1 to -1 indicates sensitivity to the appearance of vegetation on the land cover of the earth which can be applied to explain issues of vegetation amount, type, and condition [5]. To observe the change in green cover between two images a histogram is generated by plotting values of NDVI on the x-axis and the number of pixels on the y-axis. Figure. 2 shows the complete flow of given methodology.

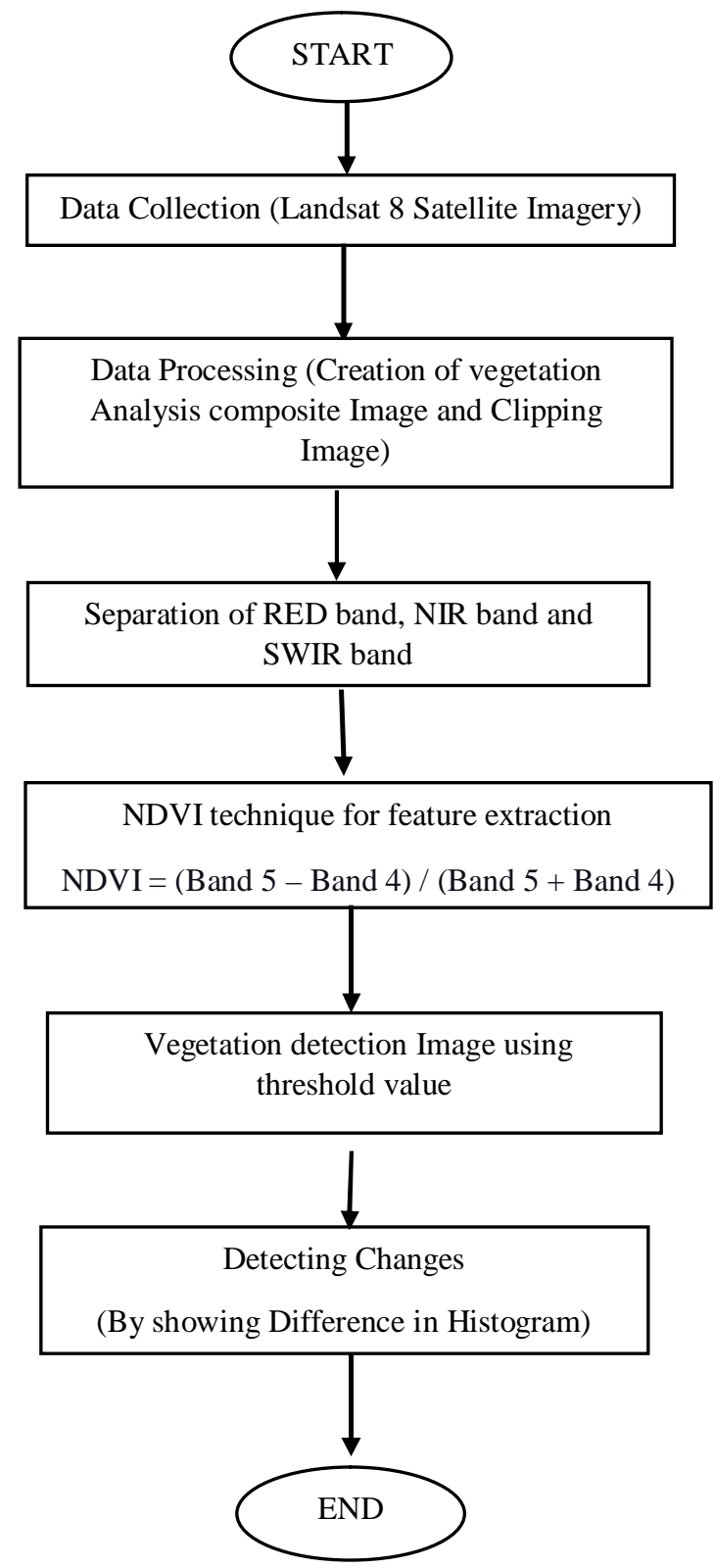

Figure 2: Flowchart of Methodology

\section{RESULTS AND DISCUSSIONS}

In result, figure 3 and figure 4 shows image of composite bands. Also figure 5 and figure 6 shows the separation of bands in composite image. In the NDVI image as shown in figure 7 and figure 8 each colour represents some specific feature, which have been presented such as red colour denote dense vegetation, orange colour represents shrubs, yellow colour denote grassland, cyan colour denote urbanization and blue colour denote water bodies presented in Nagpur image.

As a result of NDVI analysis, detecting changes by comparing the histogram of NDVI calculated satellite image, we noticed that green cover is reduced from the 
year 2014 to the year 2020 shown in figure 9 and figure 10. This is reasonably due to the urbanization of the cityNDVI indicates the health of vegetation and is higher for dense healthy vegetation and lower for scattered vegetation. The soil which has less vegetation show the lowest values and probably because from the soil the reflection is high and produces higher values in red band and low values in the NIR band, hence values of the NDVI are low. The wateravailability in the soil keeps vegetation green. Also when water availability in soil decreases, due to some environmental reason the green vegetation begins to disappear and NDVI values are decreases [17]. Therefor here values which are less than 0.1 represent less vegetation and value range from 0.1 to 0.3 shows shrub and grassland and value greater than 0.3 shows dense vegetation. Table. 2 shows a decrease in the maximum value of NDVI. Therefore we can say that result shows vegetation decreases in 2020 image as compared to the 2014 image.According to the studies that have been done before, shows that images are giving the result for all the features at NDVI value of 0.3 and 0.2.But we have selected NDVI value 0.1 as mid and it also gives good results for all the features. Therefore this research study is better as compared to the previous once.

Table 2: Difference in NDVI value

\begin{tabular}{|c|c|c|c|}
\hline $\begin{array}{c}\text { Image } \\
\text { (Year) }\end{array}$ & Rows/Column & $\begin{array}{c}\text { Min. } \\
\text { NDVI } \\
\text { value }\end{array}$ & $\begin{array}{c}\text { Max. } \\
\text { NDVI } \\
\text { value }\end{array}$ \\
\hline 2014 & $666 / 667$ & -0.25 & 0.51 \\
\hline 2020 & $666 / 667$ & -0.14 & 0.43 \\
\hline
\end{tabular}
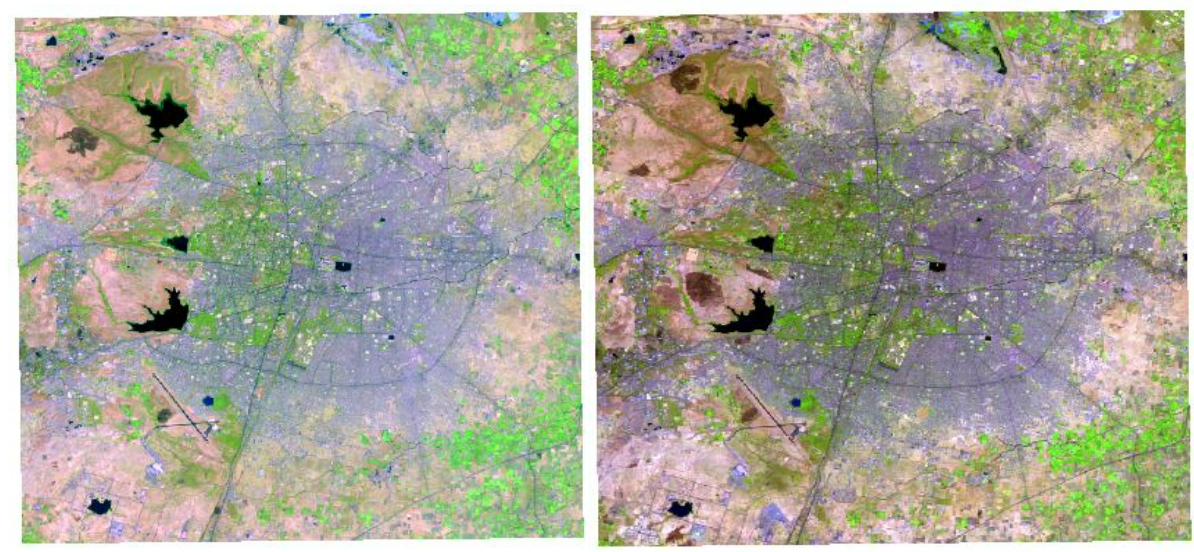

Figure 3: 3 Band Composite Image of Nagpur cityFigure 4: 3 Band Composite Image of Nagpur city

Ofyear 2014

of year 2020
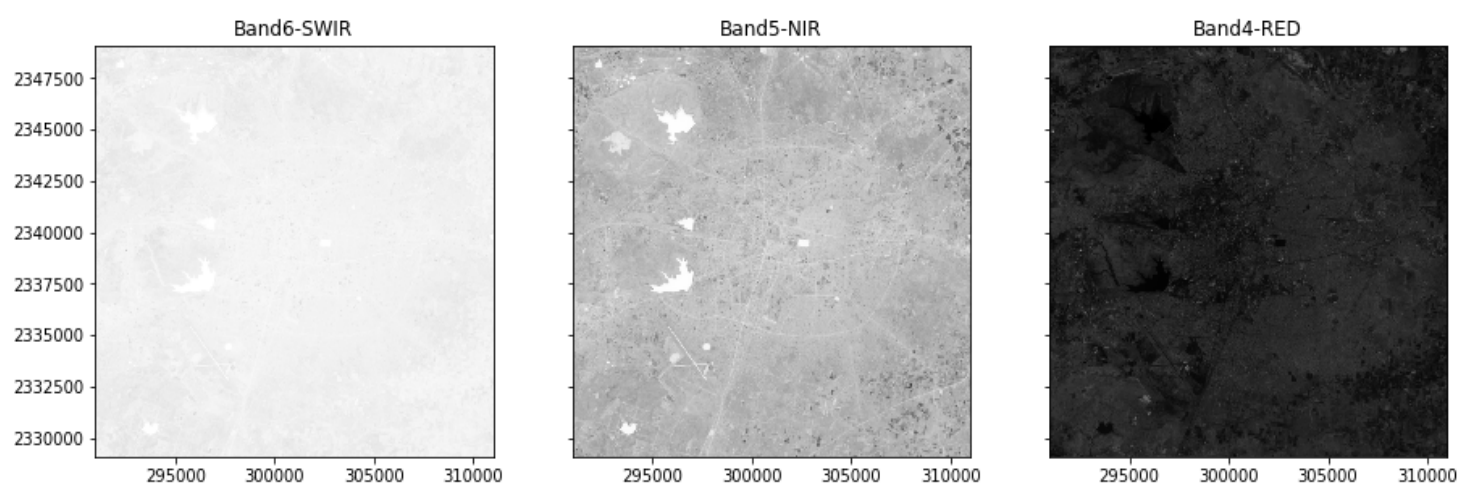

Figure 5: Band Separation of composite image for year 2014 

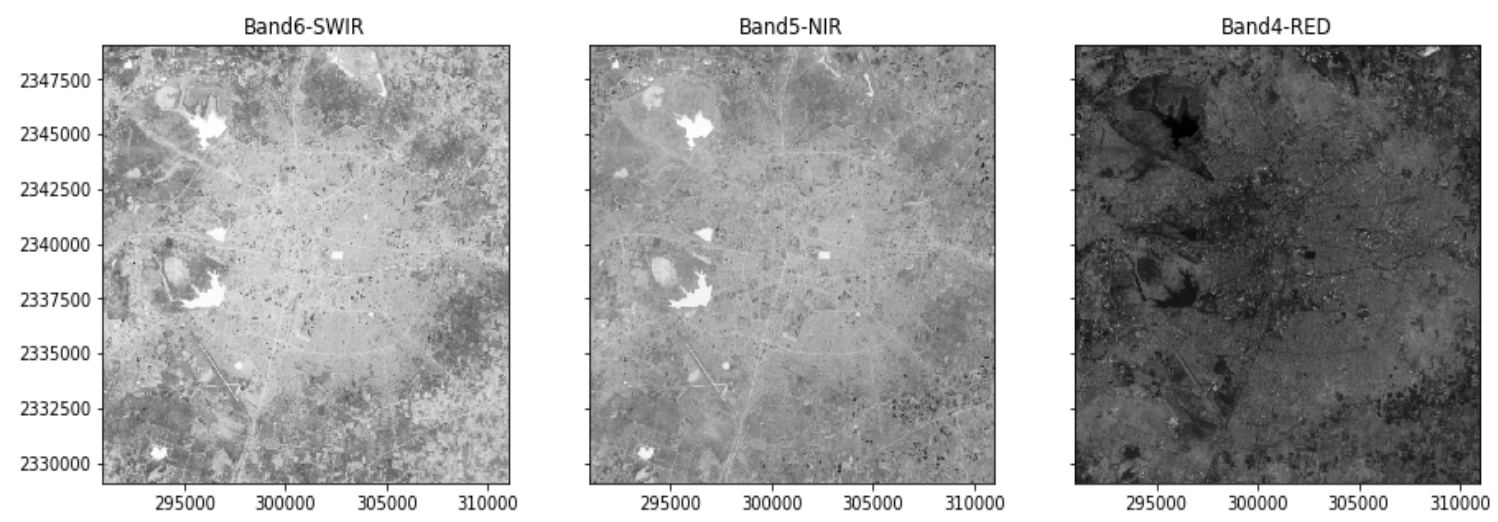

Figure 6: Band Separation of composite image for year 2020
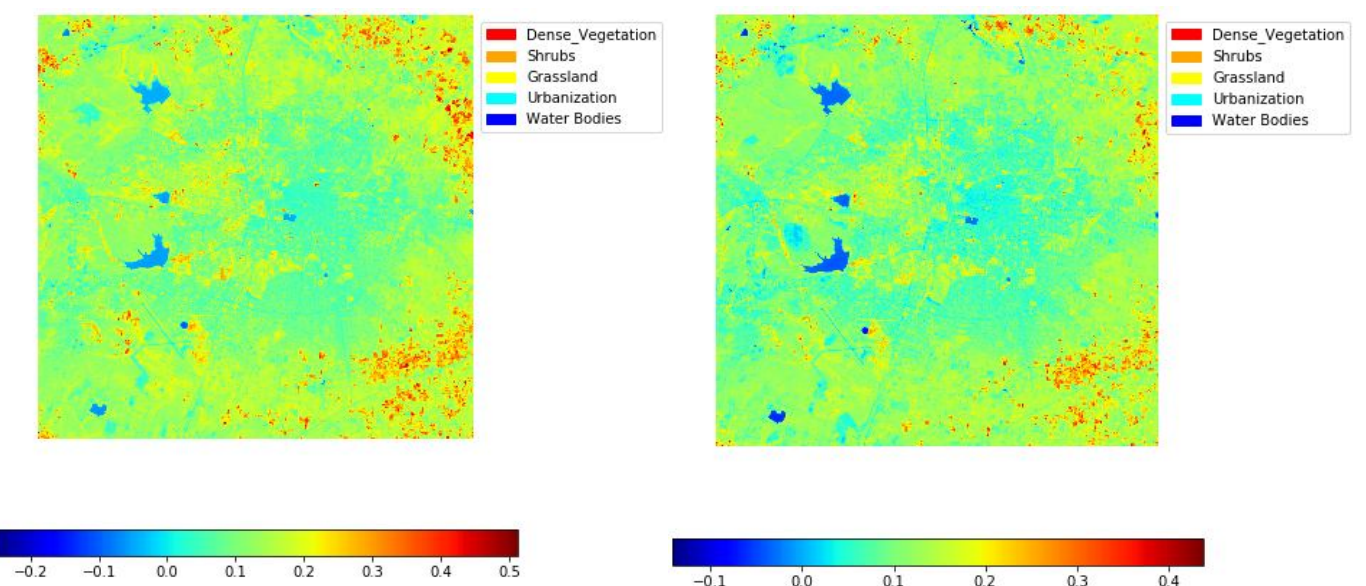

Figure 7: 2014 NDVI Image for Nagpur city

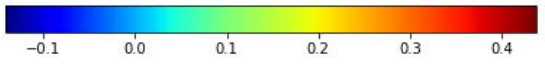

Figure 8: 2020 NDVI Image for Nagpur city

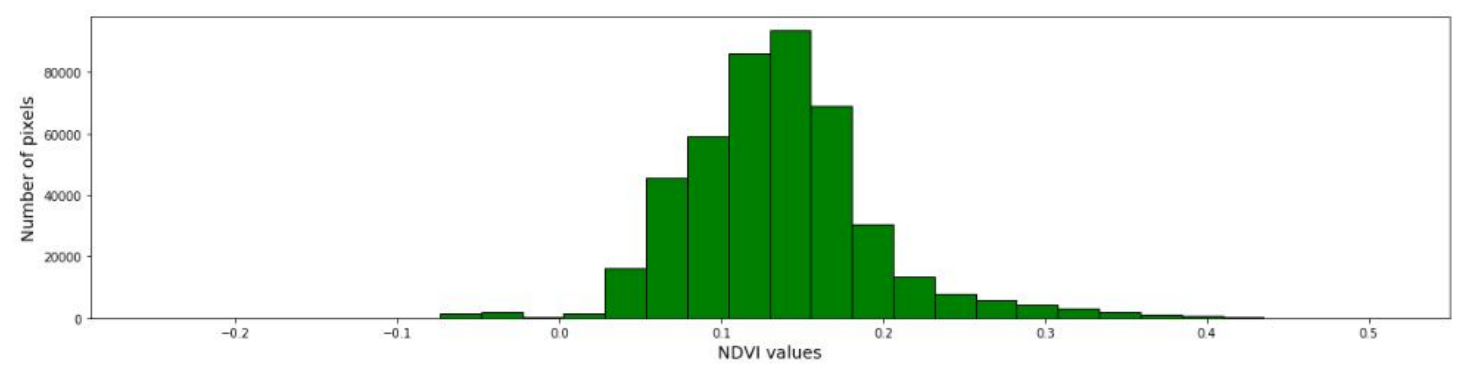

Figure 9: Histogram of NDVI Image 2014

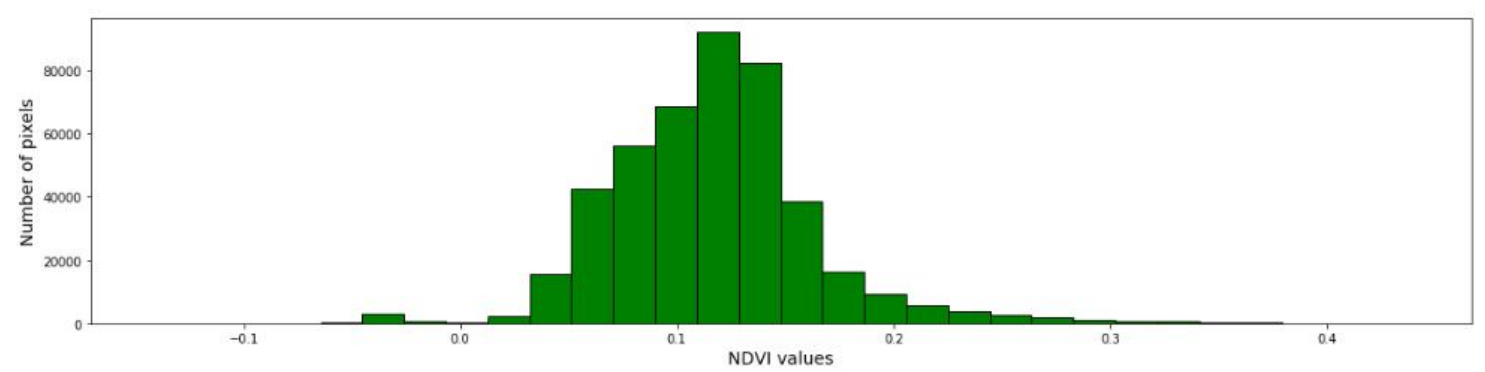

Figure 10: Histogram of NDVI Image 2020 


\section{CONCLUSION}

In this paper, to determine the differences in the index values of plant it used Landsat 8 satellite images that were taken in different years. It is used to examine the changes in vegetation cover in Nagpur city.

The practical and useful method of representing the changes recognized in various land use categories is change detection. The threshold values have been employed for feature extraction with the NDVI technique. The NDVI procedure gives excellent outcomes for vegetation differing in quantities and for distributed vegetation from a satellite image. As a result, shows a decrease in vegetation it can be seen that urbanization is increasing in this city day by day to make it a smart city. Therefore it can be concluded that the Nagpur city needs to maintain its green cover.

\section{REFERENCES}

1. A. K. Bhandaria, and G. K. Singhb. Feature extraction using normalized difference vegetation index: A case sudy of Jabalpur city, $2^{\text {nd }}$ International Conference on Communication, Computing \& Security [ICCCS-2012], Procedia Technology 6 (2012) 612 621.

2. Pavan Kumar.Monitoring of deforestation and forest degradation using remote sensing and GIS: A case study of Ranchi in Jharkhand(India), Birla Institute of Technology, Mesra, Ranchi-835215, and India.

3. M. OZYAVUZ, B. C. BILGILI, A. SALICI. Determination of vegetation changes with NDVI method, by Journal of Environmental Protection and Ecology 16, No 1, 264-273 (2015).

4. Mushtaq Ahmad Ganie and Dr.AsimaNusrath. Determining the (NDVI) vegetation indices from Landsat 8 satellite data, Internatinal Journal of Advanced research (IJAR), Article publications doi:10.21474/IJAR01/1348.

5. HimanShahabi, HasanZabihian, and AfsanehShikhi. Application of satellite images and GIS in evaluation of green space destruction in urban area (Boukan City), (IJERT)International Journal of Engineering Research \& Technology, Vol. 1 Issue 7, September - 2012 .

6. Karthik, Shivakumar B R. Change detection using image differencing: A study over area surrounding Kumta, India, $2^{\text {nd }}$ IEEE International Conference on Electrical, Computer and Communication Technologies 2017, doi: 10.1109/ICECCT.2017.8117851.

7. Carmelo Riccardo Fichera, Giuseppe Modica\& Maurizio Pollino. Land cover classification and change-detection analysis using multi-temporal remote sensed imagery and landscape metrics, European Journal of Remote Sensing (2012), 45:1, 118, DOI: 10.5721/ EuJRS20124501.

8. Wiesmair, Martin, Feilhauer, Hannes, Magiera, Anja, Otte, Annette, and Waldhardt Rainer. Estimating vegetation cover from high-resolution satellite data to assess grassland degradation in the Georgian Caucasus, Published by International Mountain
Society,doi.org/10.1659/MRD-JOURNAL-D-1500064.1

9. MeeraGandhi.G, S.Parthiban, Nagaraj Thummalu, Christy. A. Ndvi: Vegetation change detection using remote sensing and gis - A case study of Vellore District, by Third International Conference on Recent Trends in Computing 2015 (ICRTC-2015), Procedia Computer Science 57 ( 2015 ) $1199-1210$

10. M.I. Haque, R. Basak. Land cover change detection using GIS and remote sensing techniques: A Spatio - temporal study on TanguarHaor, Sunamganj Bangladesh, by The Egyptian Journal of Remote Sensing and Space Sciences (2017) 251-263.

11. R. Das Kangabam.Assessment of Land use Land cover changes in Loktak Lake in Indo-Burma biodiversity hotspot using geospatial techniques, By Egypt. J. Remote Sensing Space Sci. 22 (2019) 137143.

12. R. MeliFokeng, W. GadingaForje, V. MeliMeli. Multitemporal forest cover change detection in the Metchie-Ngoum protection forest reserve, West Region of Cameroon, The Egyptian Journal of Remote Sensing and Space Sciences, publications doi.org/10.1016/j.ejrs.2018.12.002

13. JukkaMiettinen, Hans-Jürgen Stibig, Frédéric Achard. Remote sensing of forest degradation in southeast Asia - Aiming for a regional view through 5-30 m Satellite data, by Elsevier B.V. Global Ecology and conservation, doi.org/10.1016/j.gecco.2014.07.007

14. Matthias Reusing."Change detection of natural high forests in Ethiopia using Remote Sensing and GIS techniques", by International Archives of Photogrammetry and Remote Sensing. Vol. XXXIII, Part B7. Amsterdam 2000.

15. John G. Lyon, Ding Yuan, Ross S. Lunetta, and Chris D. Elvidge. A Change detection experiment using vegetation indices, by Photogrammetric Engineering and Remote Sensing, February 1998.

16. Usman Babawuro, ZouBeiji.Satellite imagery cadastral features extractions using image processing algorithms: A viable option for cadastral science, International Journal of Computer Science IJCSI Issues, Vol. 9, Issue 4, No 2, July- 2012.

17. Anwar AbdelrahmanAly, AbdulazeamShahwanSallam, Mohammad Ibrahim Al-Wabel, and Mohammad Shayaa Al-Shayaa. Vegetation cover change detection and assessment in arid environment using multi-temporal remote sensing images and ecosystem management approach,By Copernicus Publications, doi: 10.5194/se-7-713-2016.

18. Jes'us Alvarez-Cedillo, Juan Herrera-Lozada, and Israel Rivera-Zarate. Implementation strategy of NDVI algorithm with Nvidia Thrust, by SpringerVerlag Berlin Heidelberg 2014, PSIVT 2013, LNCS 8333, pp. 184-193, 2014.

19. Haslina Hashim, Nor Aizam Adnan and ZulkifleeAbdLatif. Urban vegetation classification with NDVI threshold value method with very high resolution (VHR) pleiades imagery, by The International Archives of the Photogrammetry, Remote Sensing and Spatial Information Sciences, Volume XLII-4/W16, 2019.

20. https://gisgeography.com/landsat-8-bands-combinations 